\title{
Alkalen reflü gastritli hastalarda gastrik mukozal değişiklikler ve Helicobacter pylori enfeksiyonu
}

\author{
Gastric mucosal changes and Helicobacter pylori infection in patients with alkaline reflux gastritis
}

Enver AKBAŞ

Medipol Ünivesitesi Tip Fakültesi, Esenler Sağllk ve Uygulama Merkezi, Istanbul

Giriş ve Amaç: Alkalen reflü gastriti (safra reflüsü gastriti) olan hastalarda Helicobacter pylori enfeksiyonu, foveolar hiperplazi, intestinal metaplazi ve antral gastrik mukozal atrofinin sıklığını, safra gastriti olmayan kontrol grubu ile karşılaştırıp safranın gastrik mukozaya irritan etkisinin sonuçlarını değerlendirmeye çalıştık. Gereç ve Yöntem: Hastanemize başvuran 220 hastadan alkalen reflü gastrit tesbit edilen 115 tanesi vaka grubu, mide mukozasinda safra reflüsü gastriti olmayan 105 hasta ise kontrol grubu olarak alınd. Mide mukozasında bol miktarda konsantre veya presipite safra varlığı ile mukozal hiperemi ve ödemin endoskopik olarak görülmesi alkalen reflü gastrit olarak kabul edildi. Her iki hasta grubunda da biyopsiler alınd ve dokuda intestinal metaplazi, foveolar hiperplazi, atrofi ve Helicobacter pylori varlığı araştırıldı. Bulgular: Kontrol grubu vakalarda intestinal metaplazi görülme oranı \%9,5, safra gastriti grubunda intestinal metaplazi görülme oranı \%10,1 bulunmuştur. Gruplar arasında intestinal metaplazi görülme oranları bakımından istatistiksel olarak anlamlı farklılık saptanmamıștır. Kontrol grubunda atrofi görülme oranı \%7,6, safra gastriti grubunda atrofi görülme oranı \% 10,1 bulunmuștur. Gruplar arasında atrofi görülme oranları bakımından istatistiksel olarak anlamlı farklılık saptanmamıştır. Histopatolojik incelemede foveolar hiperplazi safra gastriti olan hastalarda \%4,3 oranında görülürken, kontrol grubu vakalarda \%2,9 oranında görülmekte olup aradaki fark istatistikse olarak anlamlı değildir. Kontrol grubu vakalarda Helicobacter pylori görülme oranı \%80,0 iken, safra gastriti grubunda \%60,6 saptanmıştır. Safra gastriti grubunda Helicobacter pylori görülme oranının, safra gastriti olmayan gruptan düşük olması istatistiksel olarak anlamlı bulunmuştur. Sonuç: Alkalen reflü gastriti olan hastalarda, foveolar hiperplazi, intestinal metaplazi ve antral gastrik mukozal atrofi sıklığı safra gastriti olamayan hastalar ile benzer bulundu. Helicobacter pylori enfeksiyonu ise safra reflüsü gastrit olan hastalarda kontrol grubu hastalara göre belirgin olarak daha düşük bulundu. $\mathrm{Bu}$ durum; safranın gastrik mukozada oluşturduğu alkali ortamın Helicobacter pylori için uygun bir vasat olmamasından kaynaklanıyor olabilir.

Anahtar kelimeler: Safra reflüsü gastriti, Helicobacter pylori, foveolar hiperplazi, intestinal metaplazi, antral gastrik atrofi

\section{GİRİs}

Safra reflüsü gastropatisi, operatif bir stoma varlığı, kolesistektomi sonrası safra deposunun ortadan kalkması, yetersiz pilorik sfinkter veya anormal duodenal motilite nedeniyle safranın geriye doğru mideye akışından kaynaklanır. Hasarın derecesi safra tuzlarına maruz kalma miktarına bağlıdır (1). Duodenogastrik reflü tanısı, endoskopi sırasında mide muko-
Background and Aims: We tried to evaluate the frequency of Helicobacter pylori infection, foveolar hyperplasia, intestinal metaplasia, and gastric mucosal atrophy of the antrum in patients with alkaline reflux gastritis (bile reflux gastritis) by comparing these patients with a control group comprised of individuals without bile reflux gastritis. We also sought to interpret the results of the irritating effects of bile on the gastric mucosa. Materials and Methods: One hundred and fifteen of 220 patients presenting to our hospital and diagnosed as having alkaline reflux gastritis were included as the patient group, and 105 patients without bile reflux gastritis were included as the control group in our study. The presence of concentrating or precipitated bile in the gastric mucosa abundantly and observation of mucosal hyperemia and edema was considered to be alkaline reflux gastritis. Biopsies were taken from both patient and control groups, and the presence of intestinal metaplasia, foveolar hyperplasia, atrophy, and Helicobacter pylori in the tissue was investigated. Results: The rates of observation of intestinal metaplasia in the control group and the bile reflux gastritis group were found to be $9.5 \%$ and $10.1 \%$; respectively. No statistically significant difference was determined between the groups regarding the rate of observation of intestinal metaplasia. The rate of observation of atrophy was found to be $7.6 \%$ and $10.1 \%$ in the control group and in the bile reflux gastritis group, respectively. No statistically significant difference was determined between the groups regarding the rate of observation of atrophy. In addition, histopathological investigation revealed foveolar hyperplasia was observed at a rate of $4.3 \%$ in patients with bile reflux gastritis, and $2.9 \%$ in the control group. The difference between these rates was not statistically significant. While the rate of observation of Helicobacter pylori in the control group was $80.0 \%$, it was determined to be $60.6 \%$ in the bile reflux gastritis group. In addition, this rate in the bile reflux gastritis group was less than the group without bile reflux gastritis and was found to be statistically significant. Conclusion: The frequency of foveolar hyperplasia, intestinal metaplasia, and gastric mucosal atrophy of the antrum in patients with alkaline reflux gastritis was found to be similar to patients without bile reflux gastritis. The frequency of Helicobacter pylori infection in patients with bile reflux gastritis was determined to be significantly less than the control group. This condition might result from unsuitability of the alkaline medium for Helicobacter pylori caused by bile in the gastric mucosa.

Key words: Bile reflux gastritis, Helicobacter pylori, foveolar hyperplasia, intestinal metaplasia, antral gastric atrophy

zasında safranın görülmesi, mide suyunda safra tuzu analizi veya radyonüklid tarama ile gösterilebilir. Foveolar hiperplazi genellikle safra reflüsü nedeniyle oluşan kimyasal gastropatilerde görülen faveolada genişleme ile karakterize histopatolojik bir bulgu olmasına rağmen spesifik ve tanısal değildir (2-4). 
Gastrik sıvıdaki safra tuzu konsantrasyonu, bu hastalarda foveolar hiperplazinin şiddeti ile korelasyon gösterir. Safra tuzları, antral metaplastik gastritin gelişimi için de bir risk faktörü gibi görünmektedir (5). Lizolesitin ve safra tuzları gastrik mukozal bariyeri bozar (6), hidrojen iyonlarının geri difüzyonuna ve mukozal hasara neden olur $(7,8)$. Helicobacter pylori (H. pylori) eş zamanlı enfeksiyonu da artmış inflamasyona neden olabilir $(9,10)$. Safra kaynaklı mukozal hasara karşı prostaglandinlerin koruyucu etkisi vardır ve bu hayvan çalışmalarında da gösterilmiştir (11).

\section{GEREÇ ve YÖNTEM}

2014-2017 yılları arasında Medipol Üniversitesi Esenler Hastanesine dispeptik yakınmalar ile başvuran 220 hastadan alkalen reflü gastrit tesbit edilen 115 tanesi vaka grubu, mide mukozasında safra reflüsü bulgusu olmayan 105 hasta ise kontrol grubu olarak alınd. Mide mukozasında bol miktarda konsantre veya presipite safra varlığı ile mukozal hiperemi ve ödemin endoskopik olarak görülmesi alkalen reflü gastrit olarak kabul edildi. Her iki hasta grubunda da biyopsiler alındı ve dokuda intestinal metaplazi, foveolar hiperplazi, gastrik mukozal atrofi ve H. pylori varlığı araştırıldı. İstatistiksel analizler için NCSS (Number Cruncher Statistical System) 2007 (Kaysville, Utah, USA) programı kullanıld. Niteliksel verilerin karşılaştırılmasında ise Pearson Ki-Kare testi, Fisher's Exact test ve Mc-Nemar uyum testi, tanı tarama testleri (Spesifisite, sensitivite vb) kullanıldı. Anlamlılık p<0,05 düzeyinde değerlendirildi.

\section{BULGULAR}

Çalışma; vakaların \%37,3'ü (n=76) erkek, \%62,7'si (n=144) kadın olmak üzere 220 olgu ile gerçekleştirilmiştir. Olguların yaşları 15 ile 85 arasında değişmekte olup, ortalama $42,43 \pm 17,03$ yldir. Kontrol grubu vakaların yaş ortalaması $38,93 \pm 12,74$ yll, safra gastriti grubu yas ortalaması 39,86 $\pm 16,72$ yıldır. Yaş ortalamalarına göre gruplar arasında istatistiksel olarak anlamlı farklılık saptanmamıştır ( $p>0,05)$.
Cinsiyet dağılımlarına göre gruplar arasında istatistiksel olarak anlamlı farklılık saptanmamıştır ( $>>0,05)$.

Olgularin \%11,1'inde (n=26) intestinal metaplazi, \%8,5'inde $(n=20)$ antral mukozal atrofi görülmüştür. Kontrol grubu vakalarda intestinal metaplazi görülme oranı \%9,5 (n=10), safra gastriti grubunda intestinal metaplazi görülme oranı \%10,1 $(\mathrm{n}=11)$ bulunmuştur. Gruplar arasında intestinal metaplazi görülme oranları bakımından istatistiksel olarak anlamlı farklılık saptanmamıştır ( $\mathrm{p}>0,05)$.

Kontrol grubunda atrofi görülme oranı $\% 7,6 \quad(n=8)$, safra gastriti grubunda atrofi görülme oranı \%10,1 (n=11) bulunmuştur. Gruplar arasında atrofi görülme oranları bakımından istatistiksel olarak anlamlı farklılık saptanmamıştır ( $p>0,05)$.

Histopatolojik incelemede foveolar hiperplazi safra gastriti olan hastalarda \%4,3 (n=5) oranında görülürken, kontrol grubu vakalarda \%2,9 (n=3) oranında görülmekte olup aradaki fark istatistiksel olarak anlamlı bulunmamıştr ( $\mathrm{p}=0,724)$.

Kontrol grubu vakalarda H. pylori görülme oranı \%80,0 (n=84) iken, safra gastriti grubunda \%60,6 (n=66) saptanmıştır. Safra gastriti grubunda H. pylori görülme oranının, safra gastriti olmayan gruptan düşük olması istatistiksel olarak anlamlı bulunmuştur ( $p=0,002 ; p<0,01)$. Bütün olgula-

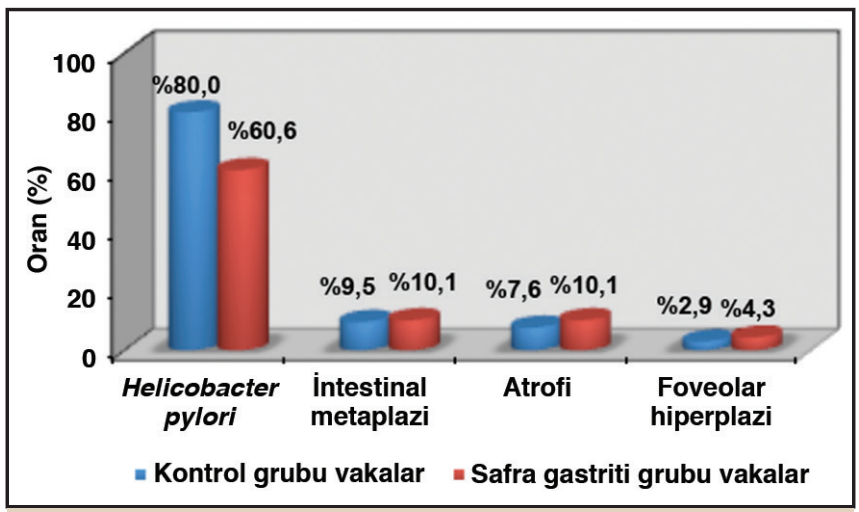

Şekil 1. Safra gastriti ve kontrol grubu vaka verilerinin grafiksel gösterimi.

Tablo 1. Hastaların endoskopik, histopatolojik özellikleri ve aldıkları tedaviler

$\begin{array}{lcccc} & & \text { Kontrol Grubu (n=105) } & \text { Safra Gastriti Grubu (n=115) } & { }^{b} p \\ \text { Yaş (yıl) } & \text { Min-Mak (Medyan) } & 17-73(37) & 15-77(37) & \\ & \text { Ort } \pm \text { Ss } & 38.93 \pm 12.74 & 39.86 \pm 16.72 & \\ \text { Cinsiyet; } \mathbf{n}(\%) & \text { Erkek } & 41(53.9) & 35(46.1) & 0.890 \\ & \text { Kadın } & 64(44.4) & 80(55.6) & 0.180 \\ \text { Helicobacter pylori; } \mathbf{n}(\%) & 84(80.0) & 66(60.6) & 0.002 * * \\ \text { Intestinal metaplazi; } \mathbf{n}(\%) & 10(9.5) & 11(10.1) & 0.889 \\ \text { Atrofi; } \mathbf{n}(\%) & 8(7.6) & 11(10.1) & 0.525 \\ \text { Foveolar hiperplazi; } \mathbf{n}(\%) & 3(2.9) & 5(4.3) & { }^{a} 0.724\end{array}$


rin \%66,8'inin ( $\mathrm{n}=157$ ) patoloji incelemesinde H. pylori saptanmıştır. Hızlı üreaz testi pozitif olanların oranı ise \%55,2 ( $\mathrm{n}=116$ ) bulunmuştur. Tablo 1 ve Şekil l'de kontrol grubu ve safra gastriti grubu hastaların verileri gösterilmektedir.

\section{TARTIŞMA}

Safra mide mukozası için kimyasal bir irritandır ve gastrik mukozada bir takım histopatolojik değişikliklere neden olabilir. Safra reflüsü gastriti, foveolar hiperplazi, lamina propriada ödem ve vazodilatasyon ve akut ve kronik inflamatuvar hücrelerin azlığı ile karakterizedir (12). Safra gastriti ile birlikte H. pylori enfeksiyonunun varlığı mukozal enfeksiyonu daha şiddetli hale getirmektedir. Safra reflüsü gastriti olan mide mukozasında $H$. pylori enfeksiyonunun sıklığı iyi araştırılmış bir konu değildir. Bizim çalışmamızda safra gastriti, $H$. pylori enfeksiyonu birlikteliğinin safra gastriti olmayan vakalardan daha az olması safranın midede alkali bir pH oluşturması nedeniyle $H$. pylori için uygun bir ortam oluşmamasından kaynaklandığı düşünülmektedir. Cai J ve ark. çalışmasında safra reflüsü gastritinde histolojik değişiklikler antrumda daha şiddetli ve kardiyaya doğru ise şiddette azalma göstermekteydi. Ayrıca asit salgısı, safra reflüsü gastriti olan hastalarda safra reflüsü olmayan hastalara göre anlamlı derecede düşük iken, serum gastrin düzeyi ise reflü gastriti olmayan gruptan daha yüksekti (13). Bazı araşrırmacılar duodenogastrik reflüde, düşük gastrik asit seviyesi ve yüksek gastrin seviyesi arasında kısır döngünün olabileceğini önermektedir. Bu da safra gastriti olan hastalarda hipoasiditide fikrini doğrulamaktadır. Bu durumda bu hastalarda " $H$. pylori eradikasyonu amaciyla verilen tedavi protokollerine oral ursodeoksikolik asid eklenmesi bu hastalarda bir taraftan mukozal inflamasyonu azaltırken diğer taraftan eradikasyon başarısını arttırır mı?" araştırılması gereken bir durumdur. Foveolar hiperplazi alkalen reflü gastritli hastalarda sık görülesine rağmen spesifik ve tanısal bir histopatolojik bulgu değildir. Bizim vakalarımızda alkalen reflü gastritli hastalarda foveolar hiperplazi daha sık görülmesine rağmen bu artış istatistiksel olarak anlamlı değildi. Nakamura ve ark.'nın çalışmasında yüksek pH ve gastrik total safra asidi konsantrasyonu intestinal metaplazi ile belirgin olarak ilişkili bulunmuştur (5). Safra gastrik mukoza için şimik bir irritan olmasına rağmen bizim vakalarımızda intestinal metaplazi ve gastrik mukozal atrofi oranlarında artışa yol açmadığı görülmüştür.

\section{KAYNAKLAR}

1. Niemelä S. Duodenogastric reflux in patients with upper abdominal complaints or gastric ulcer with particular reference to reflux-associated gastritis. Scand J Gastroenterol Suppl 1985;115:1-56.

2. Karttunen T, Niemelä S. Campylobacter pylori and duodenogastric reflux in peptic ulcer disease and gastritis. Lancet 1988;1:118.

3. Stein HJ, Smyrk TC, DeMeester TR, et al. Clinical value of endoscopy and histology in the diagnosis of duodenogastric reflux disease. Surgery 1992;112:796-803

4. Niemelä S, Karttunen T, Heikkilä J, Lehtola J. Characteristics of reflux gastritis. Scand J Gastroenterol 1987;22:349-54.

5. Nakamura M, Haruma K, Kamada T, et al. Duodenogastric reflux is associated with antral metaplastic gastritis. Gastrointest Endosc 2001;53:53-9.

6. Davenport HW. Destruction of the gastric mucosal barrier by detergents and urea. Gastroenterology 1968;54:175-81.

7. Orchard R, Reynolds K, Fox B, et al. Effect of lysolecithin on gastric mucosal structure and potential difference. Gut 1977;18:457-61.

8. Eastwood GL. Effect of pH on bile salt injury to mouse gastric mucosa. A light- and electron-microscopic study. Gastroenterology 1975;68:1456-65.

9. Loffeld RJ, Loffeld BC, Arends JW, et al. Retrospective study of Campylobacter-like organisms in patients undergoing partial gastrectomy. J Clin Pathol 1988;41:1313-5.

10. Karttunen T, Niemelä S. Campylobacter pylori and duodenogastric reflux in peptic ulcer disease and gastritis. Lancet 1988;1:118.

11. Dempsey DT, Mercer DW, Deb B, et al. Adaptive cytoprotection of gastric surface epithelial cells against injury by physiologic concentrations of bile acid. Surgery 1990; 108:348-54

12. Dixon MF. Reflux gastritis. Acta Gastroenterol Belg 1989;52:292-6.

13. Cai J, Jia BQ. Clinical characteristics of bile reflux gastritis. Zhonghua Nei Ke Za Zhi 1989;28:89-92, 126. 